\title{
Factors Associated with Prolonged Patient-Attributable Delay in the Diagnosis of Colorectal Cancer
}

\author{
Irene Zarcos-Pedrinaci, $\mathrm{MD}, \mathrm{PhD}^{1,2,3}$ \\ Teresa Téllez, PhD',2 \\ Francisco Rivas-Ruiz, BSc ${ }^{1,2}$ \\ María del Carmen Padilla-Ruiz, $\mathrm{BSc}^{1,2}$ \\ Julia Alcaide, MD, $P h D^{1,3}$ \\ Antonio Rueda, MD, $\mathrm{PhD}$ 1,2,3 \\ María Luisa Baré, MD, MPH, PhD',4 \\ María Manuela Morales Suárez-Varela, MD, PhD5,6 \\ Eduardo Briones, MD, $\mathrm{PhD}{ }^{6,7}$ \\ Cristina Sarasqueta, MD, $\mathrm{PhD}^{1,8}$ \\ Nerea Fernández-Larrea, MD,9 \\ Antonio Escobar, MD, PhD ${ }^{1,10}$ \\ José María Quintana, MD, $\mathrm{PhD}^{1,11}$ \\ Maximino Redondo, MD, PhD ${ }^{1,2}$ \\ For the REDISSEC-CARESS/CCR Group ${ }^{1, a}$
}

*A list author's affiliations appears at the end of the paper.

Correspondence: Maximino Redondo, MD, PhD

Research Unit, Hospital Costa del Sol,

Carretera de Cádiz km 187 29603,

Marbella, Málaga, Spain

Tel: $34-951976773$

Fax: 34-951976788

E-mail: mredondo@hcs.es

Received August 9, 2017

Accepted December 29, 2017

Published Online January 2, 2018

${ }^{a}$ The members of the group are listed at the end of the paper.

\section{Purpose}

The delayed diagnosis of colorectal cancer (CRC) may be attributable to sociodemographic characteristics, to aspects of tumour histopathology or to the functioning of the health system. We seek to determine which of these factors most influences prolonged patient-attributable delay (PPAD) in the diagnosis and treatment of CRC.

\section{Materials and Methods}

A prospective, multicentre observational study was conducted in 22 Spanish hospitals. In total, 1,785 patients were recruited to the study between 2010 and 2012 and underwent elective or urgent surgery. PPAD is considered to occur when the time elapsed between a patient presenting the symptom and him/her seeking attention from the primary care physician or hospital emergency department exceeds 180 days. A bivariate analysis was performed to assess differences in variables segmented by tumour location and patient delay. Multivariate logistic regression analysis was performed on the outcome variable, PPAD.

\section{Results}

The rate of PPAD among this population was $12.1 \%$. PPAD was significantly associated with altered bowel rhythm (odds ratio [OR], 1.36; 95\% confidence interval [Cl], 1.02 to 1.83) and with adenocarcinoma histology, in comparison with mucinous adenocarcinoma (OR, 2.03; $95 \% \mathrm{Cl}, 1.11$ to 3.71). Other sociocultural factors and clinicopathological features were not independent predictors of PPAD.

\section{Conclusion}

Many patients do not consider altered bowel rhythm an alarming symptom, warranting a visit to the doctor. PPAD could be reduced by improving health education, raising awareness of CRC-related symptoms.

Key words

Delay, Patients, Diagnosis, Colorectal neoplasms 


\section{Introduction}

Colorectal cancer (CRC) is one of the most prevalent neoplasms in the world. It is the third most commonly diagnosed tumour in men and the second in women, provoking an estimated 1.4 million cases and 693,900 deaths in 2012 [1].

In Spain, the national health system is universal and free of charge. Population has direct access to primary healthcare, and family physicians can derive patients to specialized medicine. Around $90 \%$ of the population use the public healthcare system, and about $18 \%$ are members of a private healthcare scheme. A mandatory CRC screening programme is applied throughout the country, except in two regions. Nonetheless, over 25,000 new cases of CRC are diagnosed and 14,000 persons die of the disease each year. It is therefore considered a major public health problem.

The detection of pre-cancerous lesions or the diagnosis of $\mathrm{CRC}$ at an early stage in asymptomatic patients, with the consequent rapid initiation of treatment, is a fundamental objective in cancer care procedures, because despite its high incidence and mortality, this is one of the tumours on which preventive measures have most effect [2]. In this respect, studies have highlighted the possible influence of diagnostic and therapeutic delays on the prognosis of patients with CRC $[3,4]$, although other research groups have reported conflicting results $[5,6]$.

In general, three phases of diagnostic delay can be identified. The first is patient-attributable delay, i.e., the period between the patient's observation of the first disease-related symptom and the moment at which the doctor is consulted. The second is medical delay, or the time elapsed between the first medical examination and referral to the specialist doctor for diagnostic tests. Finally, hospital delay is the time elapsed between this referral and the date on which the diagnosis is issued. Other models of diagnostic delay, such as Andersen's Model of Total Patient Delay, describe different phases, but also include treatment delay in the concept (delay stages: appraisal, illness, behavioural, scheduling, treatment) [7]. However, the term diagnostic delay is often used without specifying the period of time it refers to. Previous studies of delay have shown that those attributable to the patient are greater than those arising within the health system [8]. Previous studies of CRC delay have concluded that rectal bleeding is one of the factors associated with a longer delay to medical consultation, but other socio-demographic factors analysed were not found to be related to the delay [9]. However, other authors have observed an association between factors such as age, sex, educational level and marital status and delay in CRC [10]. Early recognition by primary care physicians of the digestive symptoms related to colorectal tumours and the consequent referral for study is an element of vital importance in reducing diagnostic delay. However, the delay attributable to the health system represents only a small proportion of the total diagnostic delay and the lifespan of the tumour. For this reason, our study examined factors that may influence patient-attributable diagnostic delay, which in many cases is excessive.

\section{Materials and Methods}

\section{Study design}

This descriptive cross-sectional study was conducted from 2010 to 2012, addressing a multicentre prospective cohort, based on 22 hospitals belonging to the Spanish public health system, located in six regions, or Autonomous Communities, (Andalusia, Canary Islands, Catalonia, Madrid, Valencia, and Basque Country) [11]. All regions are subject to the general health law of Spain and so there are no significant regional differences in the health care system. The study population was composed of patients diagnosed with new or incident colon cancer (CC) or rectal cancer (RC), stage 1-4, who underwent either urgent or elective surgery.

All patients were included, regardless of whether they received previous or subsequent treatment.

Inclusion criteria is as follows: (1) patients diagnosed with CC (to $15 \mathrm{~cm}$ above the anal margin) or RC (from the anal margin to $15 \mathrm{~cm}$ above it), who undergo curative and / or palliative surgery for the first time; (2) pathological diagnosis of CC or RC after biopsy performed by colonoscopy; and (3) signed informed consent provided.

Exclusion criteria is as follows: (1) patients diagnosed with CC or RC in situ; (2) tumour unresectable; (3) severe mental or physical conditions which preclude the patient from responding to questionnaires; terminal patients; patients unable to respond to questionnaires from any cause; and (4) failure to provide signed informed consent.

Patients were recruited prospectively and consecutively at each of the participating centres (Fig. 1). Following recruitment, information was collected both directly from the patients and from the corresponding medical record.

\section{Study definitions}

Prolonged patient-attributable delay (PPAD) is defined as occurring when the time elapsed between the patient's observation of the first symptom and his/her communicating this to the physician exceeds 180 days. This cut-off point is arbitrary, since no generally-agreed definition has yet been established and various time intervals are referred to in the 


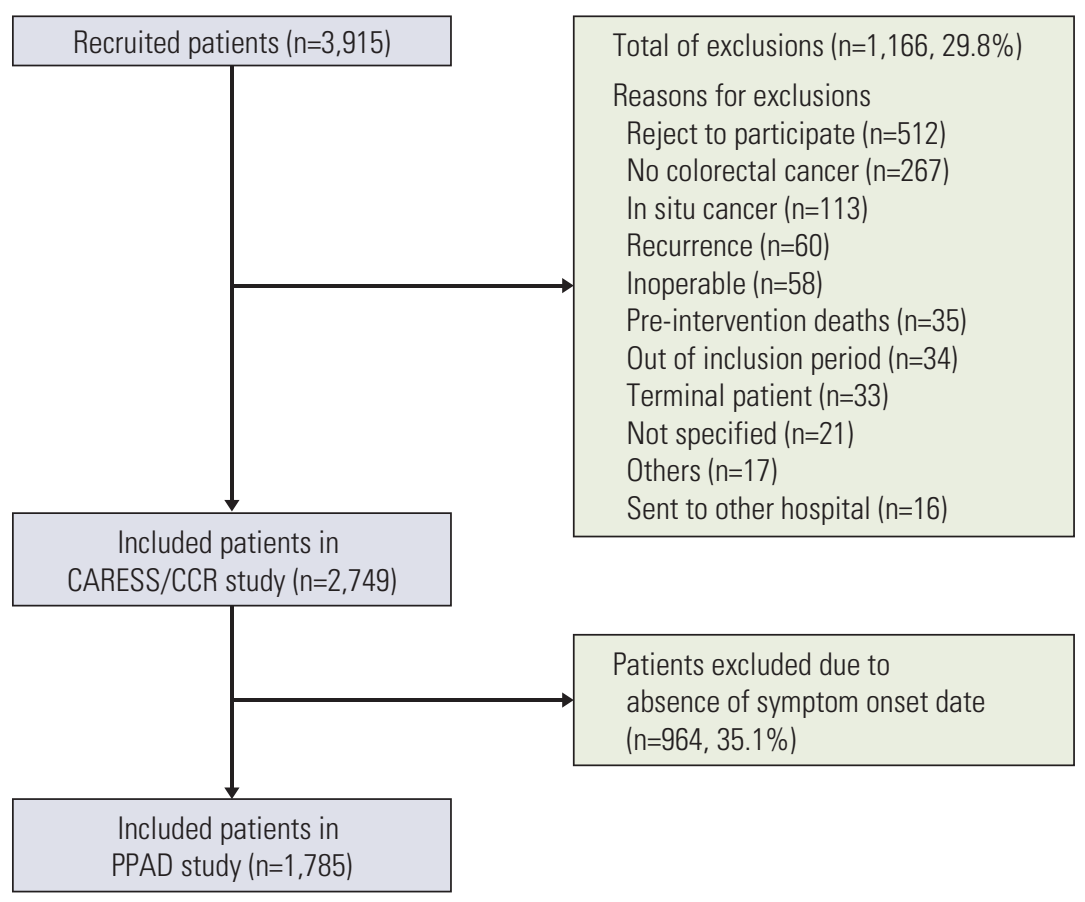

Fig. 1. Description of subject selection for the study. PPAD, prolonged patient-attributable delay.

literature [12-15], although the cut-off point of 180 days has been used in a previous report on breast cancer [16].

The anatomical location and histology of the tumours were coded in accordance with the International Classification of Diseases for Oncology (ICD-O). Classification by stages, based on the TNM staging system, was conducted in line with the recommendations of the International Union Against Cancer seventh edition.

\section{Study variables}

The clinical record of each patient was consulted to obtain data on the dependent variable: PPAD, the time elapsed since the presentation of symptoms and the moment at which the patient consulted the doctor for this reason.

The following data regarding the patients' medical record were compiled: sex, age, body mass index, smoking habit, family history of any cancer, family history of CRC, date of first contact with the hospital, date of diagnosis, date of starting treatment, existence of prior CRC screening, location of the tumour (rectum/colon), histological type (conventional adenocarcinoma/mucinous adenocarcinoma/ others), degree of histological differentiation (low/high degree), stage (tumour stage " $\mathrm{T}$ " / nodal stage " $\mathrm{N}$ ", under the TNM staging system), lymphovascular or perineural invasion, and presence of metastases.
The following variables were self-reported by the patient: initial gastrointestinal signs or symptoms (abdominal pain, bleeding, altered bowel rhythm [i.e., diarrhoea and/or constipation], perforation or intestinal obstruction), date of onset of symptoms, marital status, employment status, educational level, require assistance (receiving any help from others or from some institution), receiving social benefits (government subsidy for home help), and housing status.

\section{Statistical analysis}

A descriptive analysis was performed with measures of central tendency and dispersion for the quantitative variables and of frequency distribution for the qualitative ones. A bivariate analysis was performed to assess differences, segmented by tumour type and patient delay, using Student's t test for quantitative variables and the chi-square test for qualitative ones. Multivariate logistic regression analysis was performed on the outcome variable, PPAD. Backwards stepwise conditional analysis was applied, with an input criterion of 0.05 and an output of 0.1 . Variables with $p<0.2$ were included in the bivariate analysis, together with age, sex and tumour location. The goodness of fit was assessed by the Hosmer-Lemeshow test and the percentage of correct classification. We also checked the interaction between the variables included in the multivariate model. In view of the 
Table 1. Sociodemographic data for the total population and segmented by tumour location

\begin{tabular}{|c|c|c|c|c|}
\hline & Total $(n=1,785)$ & Colon $(n=1,266)$ & Rectal $(n=519)$ & p-value \\
\hline \multicolumn{5}{|l|}{ Sex } \\
\hline Male & $1,124(63.0)$ & $776(61.3)$ & $348(67.1)$ & 0.026 \\
\hline Female & $661(37.0)$ & $490(38.7)$ & $171(32.9)$ & \\
\hline Age (yr) & 1,782 & & & \\
\hline$<70$ & $843(47.2)$ & $555(43.9)$ & $288(55.6)$ & $<0.001$ \\
\hline$\geq 70$ & $939(52.6)$ & $709(56.1)$ & $230(44.4)$ & \\
\hline Marital status & 1,503 & & & \\
\hline Single & $106(7.1)$ & $64(6.0)$ & $42(9.5)$ & 0.007 \\
\hline Married-Partnership & $1,068(71.1)$ & $743(70.2)$ & $325(73.2)$ & \\
\hline Separated-Divorced & $74(4.9)$ & $54(5.1)$ & $20(4.5)$ & \\
\hline Widowed & $255(17.0)$ & $198(18.7)$ & $57(12.8)$ & \\
\hline Education & 1,511 & & & \\
\hline None-Primary & $1,178(78.0)$ & $832(78.0)$ & $346(77.9)$ & 1.000 \\
\hline Secondary-University & $333(22.0)$ & $235(22.0)$ & $98(22.1)$ & \\
\hline Currently employed & 1,484 & & & \\
\hline No & $1,153(77.7)$ & 809 (77.4) & $344(78.4)$ & 0.741 \\
\hline Yes & $331(22.3)$ & $236(22.6)$ & $95(21.6)$ & \\
\hline Require assistance & 1,434 & & & \\
\hline No & $538(37.5)$ & $378(37.5)$ & $160(37.5)$ & 1.000 \\
\hline Yes & $896(62.5)$ & $629(62.5)$ & $267(62.5)$ & \\
\hline Receiving social benefit & 1,453 & & & \\
\hline No & $1,235(85.0)$ & $854(83.2)$ & $381(89.4)$ & 0.003 \\
\hline Yes & $218(15.0)$ & $173(16.8)$ & $45(10.6)$ & \\
\hline Current housing status & 1,497 & & & \\
\hline Living alone in a house/Flat & $224(15.0)$ & $163(15.5)$ & $61(13.6)$ & 0.807 \\
\hline Living in a house/Flat with spouse, relative or other person & $1,229(82.1)$ & $856(81.5)$ & $373(83.4)$ & \\
\hline Living in a retirement or care home & $8(0.5)$ & $6(0.6)$ & $2(0.4)$ & \\
\hline Other situation & $36(2.4)$ & $25(2.4)$ & $11(2.5)$ & \\
\hline BMI & 1,420 & & & \\
\hline Mean \pm standard deviation & $27.6 \pm 4.8$ & $27.9 \pm 5.0$ & $26.9 \pm 4.3$ & 0.001 \\
\hline Smoking habit & 1,728 & & & \\
\hline Never smoked & $850(49.2)$ & $614(50.2)$ & $236(46.7)$ & 0.160 \\
\hline Current smoker & $212(12.3)$ & $139(11.4)$ & $73(14.5)$ & \\
\hline Ex-smoker & $666(38.5)$ & $470(38.4)$ & $196(38.8)$ & \\
\hline
\end{tabular}

Values are presented as number (\%) unless otherwise indicated.

losses in the independent variables, the fitted model coefficients were calculated from the information for all patients who presented the variables included in the model, and not from the variables included in the previous steps. The level of significance used in this analysis was $\mathrm{p}<0.05$. All statistical calculations were performed with SPSS ver. 15 (SPSS Inc., Chicago, IL).

\section{Ethical statement}

The study was performed in accordance with the good clinical practice guidelines of the Helsinki Declaration.
Informed consent was obtained from all patients to take part in the study and for their clinical records to be reviewed. This project was approved by the ethics review board of each of participating centres (reference 10/09).

The patients included were informed of the study and all gave their informed consent to perform an interview related to their symptoms, lifestyle, and medical history. 
Table 2. Clinical and pathological characteristics for the total population and segmented by tumour location

\begin{tabular}{|c|c|c|c|c|}
\hline & Total $(n=1,785)$ & Colon $(n=1,266)$ & Rectal ( $n=519)$ & p-value \\
\hline Family history of cancers & 1,617 & & & \\
\hline No & $1,023(63.3)$ & $734(64.8)$ & $289(59.6)$ & 0.051 \\
\hline Yes & $594(36.7)$ & $398(35.2)$ & $196(40.4)$ & \\
\hline Family history of CRC & 1,140 & & & \\
\hline No & $997(87.5)$ & $704(87.6)$ & $293(87.2)$ & 0.945 \\
\hline Yes & $143(12.5)$ & $100(12.4)$ & $43(12.8)$ & \\
\hline Altered bowel rhythm & 1,780 & & & \\
\hline No & $833(46.8)$ & $620(49.1)$ & $213(41.1)$ & 0.002 \\
\hline Yes & 947 (53.2) & $642(50.9)$ & $305(58.9)$ & \\
\hline Tumour location & 1,785 & & & \\
\hline Colon & $1,266(70.9)$ & & & \\
\hline Rectal & $519(29.1)$ & & & \\
\hline Size of tumour & 1,752 & & & \\
\hline Small local extension (T0-T1-T2) & $438(25.0)$ & $208(16.7)$ & $230(45.5)$ & $<0.001$ \\
\hline Large local extension (T3-T4) & $1,314(75.0)$ & $1,038(83.3)$ & $276(54.5)$ & \\
\hline Presence of nodes & 1,707 & & & \\
\hline Absence & $1,058(62.0)$ & $730(59.6)$ & $328(67.9)$ & 0.002 \\
\hline Presence & $649(38.0)$ & $494(40.4)$ & $155(32.1)$ & \\
\hline Histology & 1,759 & & & \\
\hline Adenocarcinoma & $1,578(89.7)$ & $1,118(89.0)$ & $460(91.5)$ & 0.152 \\
\hline Mucinous adenocarcinoma & $181(10.3)$ & $138(11.0)$ & $43(8.5)$ & \\
\hline Metastasis & 1,645 & & & \\
\hline Absence & $1,498(91.1)$ & $1,052(90.0)$ & $446(93.7)$ & 0.022 \\
\hline Presence & $147(8.9)$ & $117(10.0)$ & $30(6.3)$ & \\
\hline Differentiation & 1,508 & & & \\
\hline Low degree & $1,299(86.1)$ & $958(86.2)$ & $341(85.9)$ & 0.936 \\
\hline High degree & 209 (13.9) & $153(13.8)$ & $56(14.1)$ & \\
\hline Vascular invasion & 1,512 & & & \\
\hline Absence & $1,285(85.0)$ & $900(82.8)$ & $385(90.6)$ & 0.001 \\
\hline Presence & $227(15.0)$ & $187(17.2)$ & $40(9.4)$ & \\
\hline Perineural invasion & 1,470 & & & \\
\hline Absence & $1,184(80.5)$ & $832(79.2)$ & $352(84.0)$ & 0.041 \\
\hline Presence & 286 (19.5) & $219(20.8)$ & $67(16.0)$ & \\
\hline
\end{tabular}

Values are presented as number $(\%)$.

\section{Results}

A total of 1,785 patients diagnosed with CRC who met the inclusion criteria were included in this study. The mean age of this population was 68.7 years (standard deviation [SD], 11.3 ) and $63 \%$ were men. Segmenting the population by tumour location showed that both CC and RC were significantly more prevalent among the male patients. Patients diagnosed with RC were younger than those with CC (66 years vs. 69 years, $p<0.001$ ). Among patients with $C C$ or $R C$, the majority were married or in a civil partnership (CC, $70.2 \%$; RC, 73.2\%). Social benefits were more likely to be received by patients with CC than by those with $\mathrm{RC}(16.8 \%$ vs. $10.6 \%$, respectively; $\mathrm{p}=0.003)$. Body mass index was higher among the patients with CC (27.9 vs. 26.9 , respectively; $\mathrm{p}<0.001)$. Regarding the clinical characteristics observed at the time of diagnosis, tumour extension, the presence of affected lymph nodes and metastases were all greater among the patients with CC than among those with RC (stages T3-4, 83.3\% vs. 54.5\%, $\mathrm{p}<0.001$; lymph node involvement, $40.4 \%$ vs. $32.1 \%$, $\mathrm{p}=0.002$; distant metastasis, $10 \%$ vs. $6.3 \%$, $\mathrm{p}=0.022$, respectively). Vascular and perineural invasion were also more frequent in CC than in RC (17.2\% vs. $9.4 \%, \mathrm{p}<0.001$ and $20.8 \%$ vs. $16 \%, \mathrm{p}=0.041$, respectively).

Tables 1 and 2 describe the sociodemographic and clinico- 


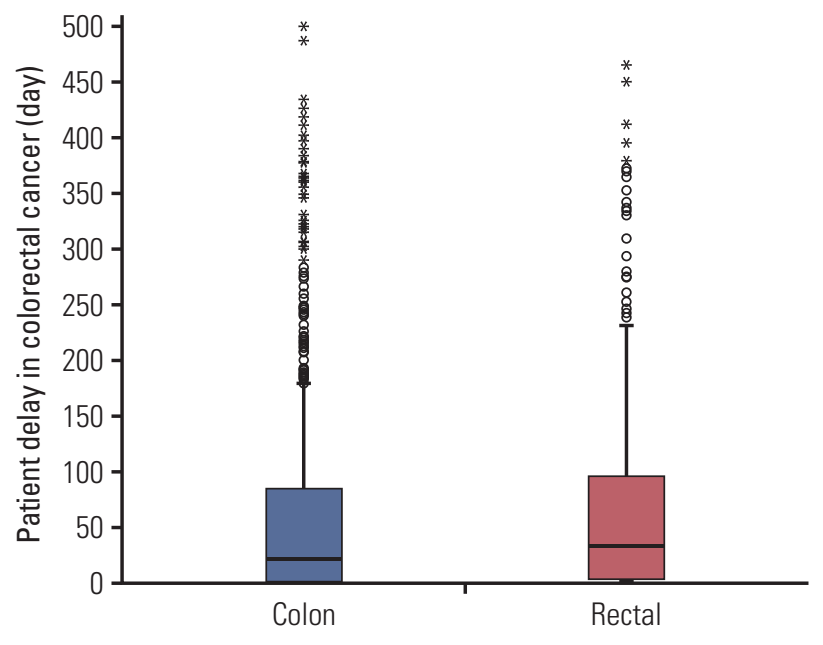

Fig. 2. Distribution of patient delays. The line within each box represents the median, and the height of each box, the interquartile range (Q3-Q1).

pathological features of the study population, segmented according to tumour location.

The distribution of patient-attributable delays, for CC and RC, was as follows. Among the 1,266 patients with CC, the median number of days elapsed from observation of symptoms until the first medical visit was 22 days, with an interquartile range of 1-77; for the 519 patients with RC, the median delay was 31 days, with an interquartile range of 2-106 (Fig. 2).

PPAD was detected in $12.1 \%$ of 1,751 patients (95\% confidence interval [CI], 10.5 to 13.6). The independent variables found in the bivariate analysis to be significantly related to a higher PPAD are shown in Table 3. After adjusting for the variables found to be significant in the raw analysis, the multivariate analysis showed that the following were indicators of a greater PPAD: adenocarcinoma-type histology (odds ratio [OR], 2.03; 95\% CI, 1.11 to 3.71 ) in comparison with mucinous-type histology; and the presence of altered bowel rhythm (OR, 1.36; 95\% CI, 1.02 to 1.83), in comparison with patients without altered bowel rhythm. The other sociodemographic and clinical variables did not present statistical significance. We also checked the interaction between the variables included in the multivariate model and no significant interactions were found.

\section{Discussion}

The duration of delay in the diagnosis and treatment of cancer patients is a matter of some controversy, and various definitions and cut-off points have been proposed. What is unquestioned is that the process is a complex one, and that it can influence disease prognosis, through factors such as tumour biology, host-tumour interaction, medical skills, the quality of the health system and the sociocultural and psychological characteristics of the patient [10].

In this multi-centre study of a population diagnosed with CRC, we analyse the patients' delay in seeking medical treatment, whether through primary care or via a hospital emergency service. Unlike previous research on diagnostic delay, the present study was conducted with a large number of patients, who were recruited prospectively and systematically. Other studies carried out on this subject in Spain have reported a relatively short average patient-attributable delay of 49 days [11]; other observers, however, have measured longer delays, of up to 130 days [16]. In this respect, too, a review of 20 studies on the patient-attributable delay observed in a study population with upper gastrointestinal cancer, described average values ranging from 14 to 225 days (7.5 months) [12-15]. Various time intervals have been suggested in definitions of PPAD, and it has even been evaluated as a continuous variable [5]. Our research group decided to use a cut-off point of 180 days taking into account our study aim, namely to determine which factors might be responsible for the patient allowing a prolonged period of time to elapse between observation of the initial symptoms related to $\mathrm{CRC}$ and seeking medical attention for this condition.

Among the 1,751 patients analyzed, the rate of PPAD observed $(12.1 \%)$ was, in fact, relatively low. The delay in seeking a first medical visit was significantly associated with the presence of altered bowel rhythm, i.e. constipation or diarrhoea. Although these signs and symptoms are known to be related to the diagnosis of CRC [17], the population at large may not be alarmed by them; they are non-specific and often attributable to other, less serious diagnoses such as altered intestinal function, changes in dietary habits or simple gastrointestinal infections. Similarly, in a previous study conducted by our group, slight or moderate digestive symptoms were associated with greater delays in seeking treatment for RC [18]. Other studies of PPAD have shown that symptoms such as mucorrhoea, bleeding and tenesmus were associated with greater delay in seeking a medical consultation, while pain motivated earlier consultation [5].

It appears, therefore, that achieving the patient's recognition of the fact that mild or moderate symptoms may be associated with CRC could be of major importance in 
Table 3. Bivariate and multivariate analysis with patient delay (180 days)

\begin{tabular}{|c|c|c|c|c|c|c|}
\hline & \multicolumn{2}{|c|}{ Patient delay } & \multicolumn{2}{|r|}{ Crude } & \multicolumn{2}{|c|}{ Adjusted $^{\text {b) }}$} \\
\hline & $\leq 180$ days & $>180$ days $^{\text {al }}$ & p-value & OR $(95 \%$ CI $)$ & p-value & OR $(95 \% \mathrm{CI})$ \\
\hline \multicolumn{7}{|l|}{ Sex } \\
\hline Male & $994(88.4)$ & $130(11.6)$ & 0.418 & 1.00 & - & - \\
\hline Female & $576(87.1)$ & 85 (12.9) & & $1.13(0.84-1.51)$ & & - \\
\hline \multicolumn{7}{|l|}{ Age (yr) } \\
\hline$<70$ & $733(87.0)$ & $110(13.0)$ & 0.201 & 1.00 & - & - \\
\hline$\geq 70$ & $833(88.9)$ & $104(11.1)$ & & $1.20(0.90-1.60)$ & & - \\
\hline \multicolumn{7}{|l|}{ Marital status } \\
\hline Single & $86(81.1)$ & $20(18.9)$ & 0.210 & 1.00 & - & - \\
\hline Married-Partnership & $943(88.3)$ & $125(11.7)$ & & $0.57(0.34-0.96)$ & & - \\
\hline Separated-Divorced & $65(87.8)$ & $9(12.2)$ & & $0.95(0.25-1.39)$ & & - \\
\hline Widowed & $22(87.1)$ & $33(12.9)$ & & $0.64(0.35-1.17)$ & & - \\
\hline \multicolumn{7}{|l|}{ Education } \\
\hline None-Primary & $1,036(87.9)$ & $142(12.1)$ & 0.570 & 1.00 & - & - \\
\hline Secondary-University & $289(86.8)$ & $44(13.2)$ & & $1.11(0.77-1.60)$ & & - \\
\hline \multicolumn{7}{|l|}{ Currently employed } \\
\hline No & $1,016(88.1)$ & 137 (11.9) & 0.204 & 1.00 & - & - \\
\hline Yes & $283(85.5)$ & $48(14.5)$ & & $1.26(0.88-1.79)$ & & - \\
\hline \multicolumn{7}{|l|}{ Require assistance } \\
\hline No & $460(85.5)$ & $78(14.5)$ & 0.144 & 1.00 & - & - \\
\hline Yes & $790(88.2)$ & $106(11.8)$ & & $0.79(0.58-1.08)$ & & - \\
\hline \multicolumn{7}{|l|}{ Receiving social benefit } \\
\hline No & $1,078(87.3)$ & $157(12.7)$ & 0.893 & 1.00 & - & - \\
\hline Yes & $191(87.6)$ & $27(12.4)$ & & $0.97(0.63-1.50)$ & & - \\
\hline \multicolumn{7}{|l|}{ Current housing status } \\
\hline Living alone in a house/Flat & $187(83.5)$ & $37(16.5)$ & 0.259 & 1.00 & - & - \\
\hline $\begin{array}{l}\text { Living in a house/Flat with spouse, } \\
\text { relative or other person }\end{array}$ & $1,085(88.3)$ & $144(11.7)$ & & $0.67(0.45-0.99)$ & & - \\
\hline Living in a retirement or care home & $8(100)$ & 0 & & - & & - \\
\hline Other situation & $31(86.1)$ & $5(13.9)$ & & $0.81(0.30-2.23)$ & & - \\
\hline \multicolumn{7}{|l|}{ BMI } \\
\hline Mean \pm standard deviation & $27.6 \pm 4.8$ & $27.8 \pm 4.9$ & 0.630 & $1.01(0.97-1.04)$ & - & - \\
\hline \multicolumn{7}{|l|}{ Smoking habit } \\
\hline Never smoked & $750(88.2)$ & $100(11.8)$ & 0.618 & 1.00 & - & - \\
\hline Current smoker & $182(85.8)$ & $30(14.2)$ & & $1.24(0.80-1.92)$ & & - \\
\hline Ex-smoker & $587(88.1)$ & 79 (11.9) & & $1.01(0.74-1.38)$ & & - \\
\hline \multicolumn{7}{|l|}{ Family history of tumours } \\
\hline No & $893(87.3)$ & $130(12.7)$ & 0.587 & 1.00 & - & - \\
\hline Yes & $524(88.2)$ & $70(11.8)$ & & $0.92(0.67-1.25)$ & & - \\
\hline \multicolumn{7}{|l|}{ Family history of CRC } \\
\hline No & $870(87.3)$ & $127(12.7)$ & 0.318 & 1.00 & - & - \\
\hline Yes & $129(90.2)$ & $14(9.8)$ & & $0.74(0.41-1.33)$ & & - \\
\hline \multicolumn{7}{|l|}{ Altered bowel rhythm } \\
\hline No & $745(89.4)$ & $88(10.6)$ & 0.067 & 1.00 & 0.039 & 1.00 \\
\hline Yes & $820(86.6)$ & $127(13.4)$ & & $1.31(0.98-1.75)$ & & $1.36(1.02-1.83)$ \\
\hline \multicolumn{7}{|l|}{ Type of tumour } \\
\hline Colon & $1,122(88.6)$ & $144(11.4)$ & 0.175 & 1.00 & - & - \\
\hline Rectal & $448(86.3)$ & $71(13.7)$ & & $1.23(0.91-1.67)$ & & - \\
\hline
\end{tabular}

(Continued to the next page) 
Table 3. Continued

\begin{tabular}{|c|c|c|c|c|c|c|}
\hline & \multicolumn{2}{|c|}{ Patient delay } & \multicolumn{2}{|c|}{ Crude } & \multicolumn{2}{|c|}{ Adjusted $^{\text {b) }}$} \\
\hline & $\leq 180$ days & $>180$ days $^{\text {a) }}$ & p-value & OR $(95 \% \mathrm{CI})$ & p-value & OR $(95 \% \mathrm{CI})$ \\
\hline \multicolumn{7}{|l|}{ Size of tumour } \\
\hline Small local extension (T0-TI-TII) & $388(88.6)$ & $50(11.4)$ & 0.797 & 1.00 & - & - \\
\hline Large local extension (TIII-TIV) & $1,158(88.1)$ & $156(11.9)$ & & $1.04(0.74-1.47)$ & & - \\
\hline \multicolumn{7}{|l|}{ Presence of nodes } \\
\hline Absence & $929(87.7)$ & $129(12.2)$ & 0.624 & 1.00 & - & - \\
\hline Presence & $575(88.6)$ & $74(11.4)$ & & $0.93(0.68-1.26)$ & & - \\
\hline \multicolumn{7}{|l|}{ Histology } \\
\hline Adenocarcinoma & $1,379(87.4)$ & $199(12.6)$ & 0.021 & $2.03(1.11-3.72)$ & 0.022 & $2.03(1.11-3.71)$ \\
\hline Mucinous adenocarcinoma & $169(93.4)$ & $12(6.6)$ & & 1.00 & & 1.00 \\
\hline \multicolumn{7}{|l|}{ Metastasis } \\
\hline Absence & $1,321(88.2)$ & $177(11.8)$ & 0.119 & 1.00 & - & - \\
\hline Presence & $136(92.5)$ & $11(7.5)$ & & $0.60(0.32-1.14)$ & & - \\
\hline \multicolumn{7}{|l|}{ Differentiation } \\
\hline Low degree & $1,137(87.5)$ & $162(12.5)$ & 0.320 & 1.00 & - & - \\
\hline High degree & $188(90.0)$ & $21(10.0)$ & & $0.78(0.48-1.27)$ & & - \\
\hline \multicolumn{7}{|l|}{ Vascular invasion } \\
\hline Absence & $1,123(87.4)$ & $162(12.6)$ & 0.628 & 1.00 & - & - \\
\hline Presence & $201(88.5)$ & $26(11.5)$ & & $0.90(0.58-1.39)$ & & - \\
\hline \multicolumn{7}{|l|}{ Perineural invasion } \\
\hline Absence & $1,036(87.5)$ & $148(12.5)$ & 0.657 & 1.00 & - & - \\
\hline Presence & $253(88.5)$ & $33(11.5)$ & & $0.91(0.61-1.36)$ & & - \\
\hline
\end{tabular}

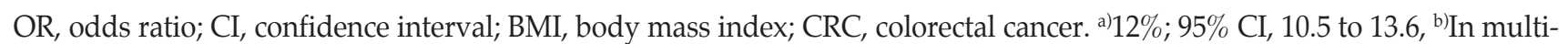
variate logistic regression with a sample of 1,751 patients, $88 \%$ correct classification. Hosmer-Lemeshow test, $\mathrm{p}=0.916$ (the proposed model fits the data observed). The variables included in the backwards stepwise conditional analysis were: sex, age, require assistance, altered bowel rhythm-previous symptom, type of tumour, histology, and metastasis.

decreasing PPAD. This view was underlined in a wide-ranging review of the literature on patient and health systemrelated factors that may influence treatment delays for upper gastrointestinal tumours. This review concluded that such delays are affected not only by awareness of symptoms but also by the recognition (or failure to recognise) that these symptoms may reflect an underlying neoplasm $[19,20]$. Another factor that could prolong delay is that of reluctance to inform the doctor of clinical signs, for fear of a diagnosis of cancer, thus provoking the concealment or redefinition of its symptoms [21-23].

In the understanding that diagnostic delay of CRC is a major public health problem that must be addressed, in 2000 the UK Department of Health introduced the "Fast-Track" or "Two Week Wait" system for patients with suspected CRC. A test/proforma system was introduced to help the general practitioner identify CRC-related symptoms; if these were observed, the patients would be referred for prompt study (within 14 days). However, this initiative did not reduce the proportion of patients with acute presentation, with advanced stages at diagnosis, or the number of cases requiring curative surgery; nor did this system influence the prognosis of patients with CC, whose survival rates remained unchanged, unlike patients with RC [24].

Other factors related to the healthcare system that may influence treatment delay include regulation, finance, direct access to secondary care and the type of primary care providers within the healthcare system [25]. There are no significant differences in these characteristics between the different regions in Spain. As mentioned before, all regions are subject to the same healthcare legislation. Therefore, a reasonable degree of homogeneity is to be expected within the healthcare system.

As in other countries, CRC screening is not yet fully implemented throughout Spain, and was much less so in 2010, when recruitment for this study began. Our findings clearly show that patient-attributable delay is greater when the first symptom is altered bowel rhythm. Accordingly, we believe significant benefits would be achieved, in terms of reducing this delay, by the systematic implantation of CRC 
screening in primary care. This screening would detect the condition even in the absence of symptoms or with mildto-moderate symptoms, cases in which patients might otherwise pay little attention and fail to consult their doctor at a sufficiently early stage.

Mucinous histology is present in 5\%-15\% of all cases of CRC. This condition is defined as being present when the mucinous component represents $>50 \%$ of the pathology sample [26]. It is associated with younger patients and with tumours of greater size and stage at diagnosis. It is often located in the right colon and accompanied by a greater presence of microsatellite instability with respect to non-mucinous histology. This tumour type presents a poorer response to cytostatic treatments in CRC and its prognosis is usually worse, especially in rectal tumours [27]. In our study, it was found to be an independent protective factor against PPAD, compared to adenocarcinoma histology, probably because the clinical course tends to be more insidious at the onset, and it is often not perceived. In consequence, when it finally becomes apparent, the condition is at a more advanced stage (III or IV) and the symptoms are more severe. Thus, patients are motivated to seek prompt medical consultation [28].

Other clinicopathological features with recognised prognostic value, such as histological differentiation, lymph node involvement, perineural involvement and the presence of metastases, were not related to PPAD. Nor was the rectal location of the tumour, in this analysis, although a previous study did find it to be a risk factor for greater treatment delay, as were the early stages (T1-T2) of CC [18].

As well as failure to recognise the severity of the symptom and its relation to $C R C$, there exists a certain culture of rejection of medical treatment, in preference for alternative approaches or focusing on preceding psychological disorders such as depression, which has been related to diagnostic and treatment delays [29]. Accordingly, our analysis also included certain socio-demographic and cultural characteristics of the population such as toxic habits (i.e., smoking), the availability of social benefits, employment status, education and marital status. However, none of these were found to be related to PPAD. An earlier report found no overall relationship between socio-economic status and delay for CRC treatment [30]. We did not include income level in our model because we did not gather this information, but we included the variable education which may give a similar information and we also found no relation. Other potentially relevant factors not included in our analyses, such as health insurance or residential area, we think that they would not have an important impact in our results, given that the healthcare insurance status is rather homogeneous for all the study participants. On the other hand, the period of delay may be affected by memory bias, regarding the patient's identification of when the first CRC-related symptom was observed.
In addition, the patient may not have correctly identified the main symptom if several were simultaneously present at the outset of the process. Moreover, we do not know what effect would be produced by a prolonged diagnostic delay $(>180$ days) on the prognosis of patients with CRC, since this was not the aim of our study; nevertheless, this question will be addressed in a future analysis, as other researchers have reported that diagnostic delay may influence survival in RC, but not in CC [5]. In contrast to previous research, our main strength is having conducted a prospective cohort study with a large number of patients and health centres, belonging to the public health system, applying consistent inclusion criteria and systematically compiling the study data.

In view of the enhanced survival and cure rates associated with early CRC diagnosis, we consider it important to determine which factors might influence any prolonged delay in a patient with CRC symptoms receiving initial medical treatment. The results obtained lead us to conclude that more health education programmes should be provided, to alert the population to the symptoms associated with CRC, such as altered bowel rhythm, and to stress the importance of early medical consultation.

\section{Conflicts of Interest}

Conflict of interest relevant to this article was not reported.

\section{Acknowledgments}

This research was partially supported by grants from REDISSEC (RD12/0001/0010 and RD16/0001/0006), Fondo de Investigaciones Sanitarias (PS09/00314, PS09/00910, PS09/00746, PS09/00805, PI09 /90460, PI09/90490, PI09/90397, PI09/90453, PI09/90441, PI13/ 0013) and Fondo Europeo de Desarrollo Regional (FEDER). We thank to Anna Colomer Gallardo for her assistance in statistical analysis.

\section{Author Details}

${ }^{1}$ Research Network on Health Services in Chronic Diseases (REDISSEC), Carlos III Health Institute, Madrid, ${ }^{2}$ Research Unit, Costa del Sol Hospital, University of Málaga, Marbella, ${ }^{3}$ Department of Oncohemathology, Costa del Sol Hospital, Marbella, ${ }^{4}$ Clinical Epidemiology and Cancer Screening, Corporació Sanitaria ParcTaulí, Sabadell, ${ }^{5}$ Department of Preventive Medicine and Public Health, University of Valencia, Valencia, ${ }^{6}$ Consortium for Biomedical Research in Epidemiology and Public Health (CIBERESP), Madrid, ${ }^{7}$ Epidemiology Unit, Sevilla District, Andalusian Regional Health Service, Sevilla, ${ }^{8}$ Research Unit, Donostia University Hospital, Biodonostia Health Research Institute, Donostia, ${ }^{9}$ Area of Environmental Epidemiology and Cancer, National Epidemiology Centre, Carlos III Health Institute, Madrid, ${ }^{10}$ Research Unit, Basurto Univer- 
sity Hospital, Bilbao, ${ }^{11}$ Research Unit, Galdakao-Usansolo Hospital, Galdakao-Usansolo Hospital, Galdakao, Spain

\section{For the REDISSEC-CARESS/CCR group}

Jose María Quintana López ${ }^{1,2}$, Marisa Baré Mañas ${ }^{1,3}$, Maximino Redondo Bautista ${ }^{1,4}$, Eduardo Briones Pérez de la Blanca ${ }^{5}$, Nerea Fernández de Larrea Baz ${ }^{6}$, Cristina Sarasqueta Eizaguirre ${ }^{1,7}$, Antonio Escobar Martínez ${ }^{1,8}$, Francisco Rivas Ruiz ${ }^{1,9}$, Maria M. MoralesSuárez-Varela ${ }^{6,10}$, Juan Antonio Blasco Amaro ${ }^{11}$, Isabel del Cura González $^{12}$, Inmaculada Arostegui Madariaga ${ }^{1,13}$, Amaia Bilbao González ${ }^{8}$, Nerea González Hernández ${ }^{1,2}$, Susana García-Gutiérrez $^{1,2}$, Iratxe Lafuente Guerrero ${ }^{1,2}$, Urko Aguirre Larracoechea ${ }^{1,2}$, Miren Orive Calzada ${ }^{1,2}$, Josune Martin Corrall ${ }^{1,2}$, Ane Antón-Ladislao ${ }^{1,2}$, Núria Torà ${ }^{1,14}$, Marina Pont ${ }^{1,14}$, María Purificación Martínez del Prado $^{15}$, Alberto Loizate Totorikaguena ${ }^{16}$, Ignacio Zabalza Estévez ${ }^{17}$, José Errasti Alustiza ${ }^{18}$, Antonio Z. Gimeno García ${ }^{19}$, Santiago Lázaro Aramburu ${ }^{20}$, Mercè Comas Serrano ${ }^{21}$, Jose María Enríquez Navascues $^{22}$, Carlos Placer Galán ${ }^{22}$, Amaia Perales ${ }^{23}$, Iñaki Urkidi Valmaña ${ }^{24}$, Jose María Erro Azkárate ${ }^{25}$, Enrique Cormenzana Lizarribar $^{26}$, Adelaida Lacasta Muñoa ${ }^{27}$, PepPiera Pibernat ${ }^{27}$, Elena Campano Cuevas ${ }^{28}$, Ana Isabel Sotelo Gómez ${ }^{29}$, Segundo Gómez-Abril ${ }^{30}$, Francisco Medina-Cano ${ }^{31}$, Antonio Rueda ${ }^{1,32}$, Julia Alcaide ${ }^{1,32}$, Arturo Del Rey-Moreno ${ }^{33}$, Manuel Jesús Alcántara ${ }^{34}$, Rafael Campo ${ }^{35}$, Alex Casalots $^{36}$, Carles Pericay ${ }^{1,37}$, Maria José Gil ${ }^{38}$, Miquel Pera ${ }^{38}$, Pablo Collera $^{39}$, Josep Alfons Espinàs ${ }^{40}$, Mercedes Martínez ${ }^{41}$, Mireia Espallargues ${ }^{1,42}$, Caridad Almazán ${ }^{6,42}$, Paula Dujovne Lindenbaum ${ }^{43}$, José María Fernández- Cebrián ${ }^{43}$, Rocío Anula Fernández ${ }^{44}$, Julio Ángel Mayol Martínez ${ }^{44}$, Ramón Cantero Cid ${ }^{45}$, Héctor Guadalajara Labajo $^{46}$, María Heras Garceau ${ }^{46}$, Damián García Olmo ${ }^{46}$, Mariel Morey Montalvo ${ }^{1,47}$

${ }^{1}$ Research Network on Health Services in Chronic Diseases (REDISSEC), Carlos III Health Institute, Madrid, ${ }^{2}$ Research Unit, GaldakaoUsansolo Hospital, Galdakao-Usansolo Hospital, Galdakao, ${ }^{3} \mathrm{Clinical}$ Epidemiology and Cancer Screening, Corporació Sanitaria ParcTaulí, Sabadell, ${ }^{4}$ Laboratory Service. Hospital Costa del Sol, Málaga, ${ }^{5}$ Epidemiology Unit, Sevilla District, Andalusian Regional Health Service, Sevilla, ${ }^{6}$ Area of Environmental Epidemiology and Cancer. National Epidemiology Centre, Carlos III Health Institute, Consortium for Biomedical Research in Epidemiology and Public Health (CIBER Epidemiología y SaludPública, CIBERESP), Madrid, ${ }^{7}$ Research Unit. Donostia University Hospital/Biodonostia Health Research Institute, Donostia, ${ }^{8}$ Research Unit, Basurto University Hospital, Bilbao, ${ }^{9}$ Epidemiology Unit, Hospital Costa del Sol, Málaga, ${ }^{10}$ Department of Preventive Medicine and Public Health, University of Valencia, Valencia, ${ }^{11}$ Health Technology Evaluation Unit, AgenciaLaínEntralgo, Madrid, ${ }^{12}$ Teaching-Research Support Unit, Planning Secretariat, Primary Health Care Management of the Regional Ministry of Health, Madrid, ${ }^{13}$ Department of Applied Mathematics, Statistics and Operational Research, University of the Basque Country, Lejona, ${ }^{14}$ Clinical Epidemiology and Cancer
Screening, Corporació Sanitaria ParcTaulí, Sabadell, ${ }^{15}$ Oncology Service, Basurto University Hospital, Bilbao, ${ }^{16} \mathrm{General}$ Surgery Service, Basurto University Hospital, Bilbao, ${ }^{17}$ Anatomo-Pathology Service, Galdakao-Usansolo Hospital, Galdakao, ${ }^{18}$ General Surgery Service, Araba University Hospital, Vitoria-Gasteiz, ${ }^{19}$ Gastroenterology Service, Canarias University Hospital, La Laguna, ${ }^{20}$ General Surgery Service, Hospital Galdakao-Usansolo, Galdakao, ${ }^{21}$ IMASHospital del Mar, Barcelona, ${ }^{22}$ General and Digestive Surgery Service. University Hospital, Donostia, ${ }^{23}$ Health Research Institute, Biodonostia, Donostia, ${ }^{24}$ General and Digestive Surgery Service, Hospital de Mendaro, Mendaro, ${ }^{25}$ General and Digestive Surgery Service, Hospital de Zumárraga, Zumárraga, ${ }^{26}$ General and Digestive Surgery Service, Hospital del Bidasoa, Hondarribia, ${ }^{27}$ Medical Oncology Service, University Hospital, Donostia, ${ }^{28}$ Institute of Biomedicine, Virgen del Rocío University Hospital, Sevilla, ${ }^{29}$ Surgery Service, Virgen de Valme University Hospital, Sevilla, ${ }^{30}$ General and Digestive Surgery Service, Hospital Dr. Pesset, Valencia, ${ }^{31}$ General and Digestive Surgery Service, Costa del Sol Health Agency, Marbella, ${ }^{32}$ Medical Oncology Service, Costa del Sol Health Agency, Marbella, ${ }^{33}$ Surgery Service, Hospital de Antequera, Antequera, ${ }^{34}$ Coloproctology Unit, General and Digestive Surgery Service, Corporació Sanitaria ParcTaulí, Sabadell, ${ }^{35}$ Digestive Diseases Department, Corporació Sanitaria ParcTaulí, Sabadell, ${ }^{36}$ Pathology Service, Corporació Sanitaria ParcTaulí, Sabadell, ${ }^{37}$ Medical Oncology Department, Corporació Sanitaria ParcTaulí, Sabadell, ${ }^{38}$ General and Digestive Surgery Service, Parc de Salut Mar, Barcelona, ${ }^{39}$ General and Digestive Surgery Service, Althaia-Xarxa Assistencial Universitaria, Manresa, ${ }^{40}$ Catalonian Cancer Strategy Unit, Department of Health, Institut Catalàd' Oncología, Barcelona, ${ }^{41}$ Medical Oncology Department, Institut Catalàd' Oncología, Barcelona, ${ }^{42}$ Agency for Health Quality and Assessment of Catalonia (AquAS), Catalonia, ${ }^{43}$ General and Digestive Surgery Service, Fundación Alcorcón University Hospital, Madrid, ${ }^{44}$ General and Digestive Surgery Service, Universitario Clínico San Carlos University Hospital, Madrid, ${ }^{45} \mathrm{Gen}$ eral and Digestive Surgery Service, InfantaSofía University Hospital, San Sebastián de los Reyes, Madrid, ${ }^{46}$ General and Digestive Surgery Service, La Paz University Hospital, Madrid, ${ }^{47}$ Research Support Unit, Primary Health Attention, Madrid, Spain 


\section{References}

1. Torre LA, Bray F, Siegel RL, Ferlay J, Lortet-Tieulent J, Jemal A. Global cancer statistics, 2012. CA Cancer J Clin. 2015;65:87108.

2. Edwards BK, Ward E, Kohler BA, Eheman C, Zauber AG, Anderson RN, et al. Annual report to the nation on the status of cancer, 1975-2006, featuring colorectal cancer trends and impact of interventions (risk factors, screening, and treatment) to reduce future rates. Cancer. 2010;116:544-73.

3. Roncoroni L, Pietra N, Violi V, Sarli L, Choua O, Peracchia A. Delay in the diagnosis and outcome of colorectal cancer: a prospective study. Eur J Surg Oncol. 1999;25:173-8.

4. Khubchandani M. Relationship of symptom duration and survival in patients with carcinoma of the colon and rectum. Dis Colon Rectum. 1985;28:585-7.

5. Pita-Fernandez S, Gonzalez-Saez L, Lopez-Calvino B, SeoanePillado T, Rodriguez-Camacho E, Pazos-Sierra A, et al. Effect of diagnostic delay on survival in patients with colorectal cancer: a retrospective cohort study. BMC Cancer. 2016;16:664.

6. Ramos M, Esteva M, Cabeza E, Llobera J, Ruiz A. Lack of association between diagnostic and therapeutic delay and stage of colorectal cancer. Eur J Cancer. 2008;44:510-21.

7. Andersen BL, Cacioppo JT. Delay in seeking a cancer diagnosis: delay stages and psychophysiological comparison processes. Br J Soc Psychol. 1995;34(Pt 1):33-52.

8. Hansen RP, Vedsted P, Sokolowski I, Sondergaard J, Olesen F. Time intervals from first symptom to treatment of cancer: a cohort study of 2,212 newly diagnosed cancer patients. BMC Health Serv Res. 2011;11:284.

9. Pedersen AF, Hansen RP, Vedsted P. Patient delay in colorectal cancer patients: associations with rectal bleeding and thoughts about cancer. PLoS One. 2013;8:e69700.

10. Macleod U, Mitchell ED, Burgess C, Macdonald S, Ramirez AJ. Risk factors for delayed presentation and referral of symptomatic cancer: evidence for common cancers. Br J Cancer. 2009;101 Suppl 2:S92-S101.

11. Quintana JM, Gonzalez N, Anton-Ladislao A, Redondo M, Bare M, Fernandez de Larrea N, et al. Colorectal cancer health services research study protocol: the CCR-CARESS observational prospective cohort project. BMC Cancer. 2016;16:435.

12. Bernal Perez M, Gomez Bernal FJ, Gomez Bernal GJ. Delay in the diagnosis of cancer. Aten Primaria. 2001;27:79-85.

13. Esteva M, Leiva A, Ramos M, Pita-Fernandez S, GonzalezLujan L, Casamitjana M, et al. Factors related with symptom duration until diagnosis and treatment of symptomatic colorectal cancer. BMC Cancer. 2013;13:87.

14. Hallissey MT, Allum WH, Jewkes AJ, Ellis DJ, Fielding JW. Early detection of gastric cancer. BMJ. 1990;301:513-5.

15. Irving MJ, Lamb PJ, Irving RJ, Raimes SA. Speeding up the diagnosis of oesophago-gastric cancer. Nurs Times. 2002;98: 35-7.

16. Redondo M, Rodrigo I, Pereda T, Funez R, Acebal M, PereaMilla E, et al. Prognostic implications of emergency admission and delays in patients with breast cancer. Support Care Can- cer. 2009;17:595-9.

17. Allgar VL, Neal RD. Delays in the diagnosis of six cancers: analysis of data from the National Survey of NHS Patients: Cancer. Br J Cancer. 2005;92:1959-70.

18. Del Giudice ME, Vella ET, Hey A, Simunovic M, Harris W, Levitt C. Systematic review of clinical features of suspected colorectal cancer in primary care. Can Fam Physician. 2014;60: e405-15.

19. Zarcos-Pedrinaci I, Fernandez-Lopez A, Tellez T, Rivas-Ruiz F, Rueda A, Morales Suarez-Varela MM, et al. Factors that influence treatment delay in patients with colorectal cancer. Oncotarget. 2017;8:36728-42.

20. Macdonald S, Macleod U, Campbell NC, Weller D, Mitchell E. Systematic review of factors influencing patient and practitioner delay in diagnosis of upper gastrointestinal cancer. Br J Cancer. 2006;94:1272-80.

21. Gullo L, Tomassetti P, Migliori M, Casadei R, Marrano D. Do early symptoms of pancreatic cancer exist that can allow an earlier diagnosis? Pancreas. 2001;22:210-3.

22. Hackett TP, Cassem NH, Raker JW. Patient delay in cancer. N Engl J Med. 1973;289:14-20.

23. Van Hout AM, de Wit NJ, Rutten FH, Peeters PH. Determinants of patient's and doctor's delay in diagnosis and treatment of colorectal cancer. Eur J Gastroenterol Hepatol. 2011;23: 1056-63.

24. Thornton L, Reader H, Stojkovic S, Allgar V, Woodcock N. Has the 'Fast-Track' referral system affected the route of presentation and/or clinical outcomes in patients with colorectal cancer? World J Surg Oncol. 2016;14:158.

25. Brown S, Castelli M, Hunter DJ, Erskine J, Vedsted P, Foot C, et al. How might healthcare systems influence speed of cancer diagnosis: a narrative review. Soc Sci Med. 2014;116:56-63.

26. Kim SH, Shin SJ, Lee KY, Kim H, Kim TI, Kang DR, et al. Prognostic value of mucinous histology depends on microsatellite instability status in patients with stage III colon cancer treated with adjuvant FOLFOX chemotherapy: a retrospective cohort study. Ann Surg Oncol. 2013;20:3407-13.

27. Park JS, Huh JW, Park YA, Cho YB, Yun SH, Kim HC, et al. Prognostic comparison between mucinous and nonmucinous adenocarcinoma in colorectal cancer. Medicine (Baltimore). 2015;94:e658.

28. Shin US, Yu CS, Kim JH, Kim TW, Lim SB, Yoon SN, et al. Mucinous rectal cancer: effectiveness of preoperative chemoradiotherapy and prognosis. Ann Surg Oncol. 2011;18: 2232-9.

29. Glimelius B, Tiret E, Cervantes A, Arnold D; ESMO Guidelines Working Group. Rectal cancer: ESMO Clinical Practice Guidelines for diagnosis, treatment and follow-up. Ann Oncol. 2013;24 Suppl 6:vi81-8.

30. Langenbach MR, Schmidt J, Neumann J, Zirngibl H. Delay in treatment of colorectal cancer: multifactorial problem. World J Surg. 2003;27:304-8. 